\title{
MicroRNA-199a-5p suppresses cell proliferation, migration and invasion by targeting ITGA3 in colorectal cancer
}

\author{
LIJUN TIAN $^{1 *}$, MINGTONG CHEN $^{2 *}$, QIANG HE $^{1}$, QIULIANG YAN $^{3}$ and CHUNBAO ZHAI ${ }^{1}$ \\ ${ }^{1}$ Department of Colorectal and Anus Surgery, Shanxi Provincial People's Hospital, Taiyuan, Shanxi 030001; \\ Departments of ${ }^{2}$ Gastroenterology and ${ }^{3}$ General Surgery, Jinhua People's Hospital, Jinhua, Zhejiang 321000, P.R. China
}

Received September 10, 2019; Accepted March 4, 2020

DOI: $10.3892 / \mathrm{mmr} .2020 .11323$

\begin{abstract}
As a member of the integrin family, integrin $\alpha 3 \beta 1$ (ITGA3) has been linked to intercellular communication and serves an important role in the signaling among cells and the extracellular matrix. MicroRNA (miR)-199a-5p has been demonstrated to be related to the pathogenesis and progression of multiple malignant diseases. However, the biological functions of miR-199a-5p and ITGA3 in colorectal cancer (CRC) have rarely been reported. The aim of the present study was to explore the roles of miR-199a-5p and ITGA3 in CRC. Immunohistochemistry staining and western blotting were applied to detect the protein expression of ITGA3 in CRC tissues and cells. Reverse transcription-quantitative PCR was performed to investigate the expression of miR-199a-5p and ITGA3 mRNA. HCT-116 cells were transfected with miR-199a-5p mimics, mimics control, short hairpin RNA targeting ITGA3, or pcDNA-ITGA3 for the functional experiments. Dual luciferase reporter assay was applied to confirm whether miR-199a-5p targeted the 3' untranslated region (3'UTR) of ITGA3. The MTT, Transwell and wound healing assays were used to evaluate the proliferation, invasion and migration of CRC cells. Immunofluorescence assay was used to monitor the epithelial-mesenchymal transition (EMT) biomarker expression. The results demonstrated downregulation of miR-199a-5p and upregulation of ITGA3 in CRC tissues and cell lines. miR-199a-5p mimics and knockdown of ITGA3 suppressed the proliferation, invasion and migration of CRC cells. Bioinformatics analysis and luciferase
\end{abstract}

Correspondence to: Dr Qiuliang Yan, Department of General Surgery, Jinhua People's Hospital, 288 Xinhua Street, Wucheng, Jinhua, Zhejiang 321000, P.R. China

E-mail: yanq1623@163.com

Dr Chunbao Zhai, Department of Colorectal and Anus Surgery, Shanxi Provincial People's Hospital, 29 Shuangta Temple Street, Taiyuan, Shanxi 030001, P.R. China

E-mail: zcb4940700@163.com

*Contributed equally

Key words: miR-199a-5p, ITGA3, migration, invasion, proliferation reporter assay indicated that miR-199a-5p targeted the 3'UTR of the ITGA3 transcript, and overexpression of ITGA3 reversed the tumor-suppressive effects of miR-199a-5p elevation. In addition, the immunofluorescence assay suggested that miR-199a-5p mimics suppressed the EMT of CRC cells, whereas the overexpression of ITGA3 restored this effect. In conclusion, miR-199a-5p may act as a tumor suppressor by targeting and negatively regulating ITGA3 in CRC.

\section{Introduction}

The genome profile stability serves a crucial role in the maintenance of human health. Emerging evidence has indicated that the dysregulation of gene expression occurs in multiple diseases, such as cardiovascular disease (1), Parkinson's disease (2) and malignant tumors $(3,4)$. Colorectal cancer (CRC) is a common malignant disease of the gastrointestinal tract; the incidence and mortality of CRC has been steadily declining for the past two decades (5), with an exception of younger adults ( $<50$ years), which is possibly related to an increase in cancer screening and improved therapeutic modalities (5). Currently, the treatment of CRC mainly includes surgical resection, radiotherapy and chemotherapy (6). Another modern aspect of CRC treatment is immunotherapy with programmed cell death protein 1 (PD-1) inhibitors nivolumab and pembrolizumab, which currently constitute the standard of care for the treatment of chemotherapy-resistant microsatellite instability-high/mismatch repair-deficiency CRC (7). Patients with early stage CRC usually have favorable prognoses after surgery, yet the prognoses of most patients at a late stage are poor due to the tumor invasion and metastasis (8). Furthermore, epithelial-mesenchymal transition (EMT) is a key cellular event for various biological processes including cell division, fetal development and wound healing $(9,10)$. In malignant diseases, EMT is usually considered as an important factor for promoting cell invasion, migration and drug resistance (10). The expression levels of $\mathrm{N}$-cadherin and E-cadherin are important biomarkers of EMT progress (11). Previous studies have reported that EMT participates during colon cancer carcinogenesis and development (12); therefore, identifying novel therapeutic targets to prevent EMT may be valuable for CRC.

MicroRNAs (miRNAs) are a type of short RNA sequences without the capability of encoding proteins, 
usually 18-25 nucleotides long (13). miRNAs post-transcriptionally inhibit target mRNA expression by binding to their 3'untranslated regions (3'UTRs) (14). miRNAs participate in the regulation of various biological events, including tumor growth, invasion, metastasis and angiogenesis (15). miRNA (miR)-199a-5p belongs to the miR-199a family, which has been demonstrated to participate in the progression of multiple diseases such as acute myeloid leukemia (16) and cervical cancer (17). Dai et al (18) reported that miR-199a-5p prevented hepatocyte damage induced by bile acid. Furthermore, miR-199a-5p was downregulated in non-small cell lung cancer (19). miR-199a-5p is associated with CRC cell proliferation via targeting ROCK1 (20) and FZD6 (21); however, the impact of miR-199a-5p on other signaling pathways during CRC is not completely understood.

Integrins are a class of transmembrane receptors, and their main function is to participate in the regulation of cellular adhesion (22). Integrins are dimers consisting of $\alpha(120-185 \mathrm{kDa})$ and $\beta(90-110 \mathrm{kDa})$ subunits; they can receive mechanical stimuli the from extracellular matrix and transit these stimuli into downstream signals to regulate cell proliferation, adhesion and migration $(23,24)$. Integrin $\alpha 3 \beta 1$ (ITGA3) has been reported to be upregulated and correlated with poor prognosis in oral squamous cell carcinoma and pancreatic cancer $(25,26)$. Moreover, ITGA3 promotes EMT and cancer stemness during breast cancer (27); therefore, ITGA3 may be a potential target for anticancer therapy.

The present study aimed to identify the role of miR-199aa-5p during CRC carcinogenesis and progression. Using bioinformatics analysis, several potential targets of miR-199a-5p were identified, among them, ITGA3 was further investigated.

\section{Materials and methods}

Samples. A total of 101 pairs of tumor and para-tumor tissue ( $2 \mathrm{~cm}$ away from the tumor margin) specimens obtained from 49 male and 52 female patients (age range, 38-79 years) were collected from Jinhua People's Hospital between March 2018 and October 2019. This research did not cause any extra medical expenses or pain. The samples were grouped according to the TNM phasing: 37 cases of T1, 43 cases of T2, 11 cases of T3 and 10 cases of T4 tumors. All samples were collected with the written informed consent of patients, and the study was approved by the Ethics Committee of Jinhua People's Hospital. All tissues were stored at $-80^{\circ} \mathrm{C}$.

Cell culture. Human CRC cell lines HCT-116 and Caco-2 and the normal colon epithelial cell line NCM460 were obtained from the Cell Bank of Chinese Academy of Sciences (Shanghai, China). NCM460, HCT-116 and Caco-2 cells were cultured in McCoy's 5A medium (Thermo Fisher Scientific, Inc.) supplemented with 10\% FBS (Gibco: Thermo Fisher Scientific, Inc.) and $1 \%$ penicillin/streptomycin in a humidified atmosphere containing $5 \% \mathrm{CO}_{2}$ at $37^{\circ} \mathrm{C}$.

Cell transfection. Cells (1x105/well) were plated into 6-well plates and cultured for $24 \mathrm{~h}$, and subsequently transfected with miR-199a-5p mimics negative control (miR-199a-5p NC; sense, 5'-UUCUCCGAACGUGUCACGUTT-3' and antisense, 5'-ACGUGACACGUUCGGAGAATT-3'),
miR-199a-5p mimics (sense, 5'-CCCAGUGUUCAGACU ACCUGUUC-3' and antisense, 5'-ACAGGUAGUCUGAAC ACUGGGUU-3'), pcDNA-NC (empty), pcDNA-ITGA3 (Shanghai GenePharma Co., Ltd.), short hairpin RNA (sh)-NC or sh-ITGA3 (pLVX-sh-ITGA3 plasmids supplied by Shanghai GenePharma Co., Ltd.) using Lipofectamine ${ }^{\circledR} 2000$ (Invitrogen; Thermo Fisher Scientific, Inc.), according to the manufacturer's instructions. Briefly, Firstly, $1 \mu \mathrm{g}$ nucleic acid fragment and $2 \mu \mathrm{l}$ Lipofectamine 2000 were mixed with $0.5 \mathrm{ml}$ serum-free McCoy's 5A medium. After incubation for $15 \mathrm{~min}$ at room temperature, the mixture was added to each well with $4 \mathrm{ml}$ serum-free medium. Following incubation for $24 \mathrm{~h}$, the culture medium was replaced with McCoy's 5A medium containing $10 \%$ FBS. After $24-72 \mathrm{~h}$, cells were used for subsequent experiments. pcDNA-ITGA3 transfection efficiency is presented in Figs. S1 and S2.

MTT assay. HCT-116, Caco-2 and NCM460 cells were seeded in 96-well plates at the density of $1 \times 10^{4}$ cells/well. The cells were incubated at $37^{\circ} \mathrm{C}$ for $24 \mathrm{~h}$ after the cells were attached. Subsequently, the medium was removed, and MTT $(0.5 \mathrm{mg} / \mathrm{ml})$ diluted in medium was added to the wells. After $3 \mathrm{~h}$, the medium containing MTT was removed and $200 \mu \mathrm{l}$ DMSO was added. Finally, the absorbance was detected on a microplate reader (Thermo Fisher Scientific, Inc.) at $595 \mathrm{~nm}$. The experiments were performed independently at last three times.

Wound healing assay. Wound healing assay was used to investigate the cell migration in the different groups. Following treatment with miR-199a-5p mimics, mimics NC, sh-NC or sh-ITGA3, HCT-116 cells were collected and seeded (1x10\% $/$ well) in 6-well plates for $24 \mathrm{~h}$, followed by scratching with a $10-\mu l$ pipette tip, and then images of the scratches were captured under a light microscope. Following $24 \mathrm{~h}$ incubation with McCoy's 5A medium containing 1\% FBS, the migration of the HCT-116 cells were calculated using the following formula: $\left(\mathrm{S}_{0 \mathrm{~h}}-\mathrm{S}_{24 \mathrm{~h}}\right) / \mathrm{S}_{0 \mathrm{~h}} \times 100 \%$, where $\mathrm{S}$ represents the width of the wound.

Transwell assay. The Transwell assay was used to investigate cell invasion after treatment with miR-199a-5p mimics, mimics NC, sh-NC or sh-ITGA3. The upper chambers of the Transwell plates were pre-coated with $50 \mu 1$ 1:1 mixture of Matrige ${ }^{\circledR}$ and McCoy's 5A medium at $37{ }^{\circ} \mathrm{C}$ for $1 \mathrm{~h}$. Briefly, HCT-116 cells were collected and seeded in serum-free McCoy's 5A medium, and then re-seeded $\left(2 \times 10^{4}\right.$ cells/well) into the upper chambers, while McCoy's 5A medium containing 20\% FBS was placed in the lower chambers. Following incubation at $37^{\circ} \mathrm{C}$ for $24 \mathrm{~h}$, non-invasive cells were removed using a sterile cotton swab and the invading cells were fixed with $4 \%$ paraformaldehyde at room temperature for $10 \mathrm{~min}$. Subsequently, invading cells were stained using $0.1 \%$ crystal violet at room temperature for $20 \mathrm{~min}$ and observed using a light microscope (magnification, $\mathrm{x} 400$ ).

Total RNA extraction and reverse transcription-quantitative PCR (RT-qPCR). miR-199a-5p and ITGA3 mRNA expression levels were detected by RT-qPCR. Total RNA in the different groups was extracted using the TRIzol ${ }^{\circledR}$ Reagent kit (Invitrogen; Thermo Fisher Scientific, Inc.), according to the 
manufacturer's instructions. Total RNA was reverse transcribed into cDNA using the RT Reagent kit (TransGen Biotech) or the miRNA First-Strand cDNA Synthesis SuperMix kit (TransGen Biotech). The following thermocyclcing conditions were used for reverse transcription: $42^{\circ} \mathrm{C}$ for $15 \mathrm{~min}$, followed by $5 \mathrm{sec}$ at $85^{\circ} \mathrm{C}$ and storage at $4^{\circ} \mathrm{C}$ until further analysis. Subsequently, qPCR was preformed using an ABI Detection System (Applied Biosystems; Thermo Fisher Scientific, Inc.) and SYBR ${ }^{\circledR}$ Green Premix Ex Taq ${ }^{\mathrm{TM}}$ (Takara Bio, Inc.). The following thermocycling conditions were used for qPCR: Initial denaturation for $30 \mathrm{sec}$ at $95^{\circ} \mathrm{C}$; followed by 40 cycles of $5 \mathrm{sec}$ at $95^{\circ} \mathrm{C}$ and $30 \mathrm{sec}$ at $60^{\circ} \mathrm{C}$; and dissociation at $95^{\circ} \mathrm{C}$ for $15 \mathrm{sec}, 60^{\circ} \mathrm{C}$ for $30 \mathrm{sec}$ and $95^{\circ} \mathrm{C}$ for $15 \mathrm{sec}$. The primer sequences used for qPCR were as follows: ITGA3 forward, 5'-TCAACCTGG ATACCCGATTCC-3' and reverse, 5'-GCTCTGTCTGCC GATGGAG-3'; miR-199a-5p forward:, 5'-TCAAGAGCAATA ACGAAAAATGT-3' and reverse, 5'-GCTGTCAACGATACG CTACGT-3'; U6 forward, 5'-CGCTTCGGCAGCACATATAC TA-3' and reverse, 5'-CGCTTCACGAATTTGCGTGTCA-3'; GAPDH forward, 5'-AGGTCGGTGTGAACGGATTTG-3' and reverse, 5'-GGGGTCGTTGATGGCAACA-3'. mRNA and miRNA expression levels were quantified using the $2^{-\triangle \Delta \mathrm{Cq}}$ method and normalized to the internal reference genes GAPDH and U6, respectively (28).

Total protein extraction and western blotting. After treatment with miR-199a-5p mimics, mimics NC, sh-ITGA3 or sh-NC, HCT-116 cells were lysed using RIPA buffer (Nanjing KeyGen Biotech Co., Ltd.). Subsequently, protein samples (25 $\mu \mathrm{g}$ per lane) were quantified using a Bicinchoninic Acid Assay kit (Beyotime Institute of Biotechnology), separated via $10 \%$ SDS-PAGE and transferred to PVDF membranes. The membranes were blocked with $5 \%$ skim milk at room temperature for 1-2 h. Subsequently, the membranes were incubated with an anti-ITGA3 antibody (cat. no. ab131055; 1:500; Abcam) and an anti-GAPDH antibody (cat. no. 10494-1-AP; 1:2,000; ProteinTech Group, Inc.) at $4^{\circ} \mathrm{C}$ overnight. Following primary incubation, the membranes were incubated with a horseradish peroxidase-conjugated Affinipure Goat Anti-Rat IgG (H+L) secondary antibody (cat. no. SA00001-15; 1:2,000; ProteinTech Group, Inc.) at $37^{\circ} \mathrm{C}$ for $1 \mathrm{~h}$. Protein bands were visualized using Western Bright ${ }^{\mathrm{TM}}$ ECL (cat. no. K-12045-D50; Advasta, Inc.) and analyzed using ImageJ software (version 1.8.0; National Institutes of Health) with GAPDH as the loading control.

Immunofluorescence assay. The expression levels of E-cadherin and N-cadherin were evaluated by an immunofluorescence assay. Following co-transfection with pcDNA-ITGA3 and miR-199a-5p mimics or mimics NC, HCT-116 cells were fixed with $4 \%$ paraformaldehyde at $4^{\circ} \mathrm{C}$ for $24 \mathrm{~h}$. Subsequently, cells were incubated with the following primary antibodies at $4^{\circ} \mathrm{C}$ overnight: Anti-E-cadherin (cat. no. ab40772; 1:1,000; Abcam) and anti-N-cadherin (cat. no. ab18203; 1:1,000; Abcam). Following primary incubation, cells were incubated with an anti-Rabbit IgG H\&L horseradish peroxidase-conjugated secondary antibody (cat. no. ab6721; 1:1,000; Abcam) at $37^{\circ} \mathrm{C}$ for $30 \mathrm{~min}$. Subsequently, cells were stained with DAPI at room temperature for $5 \mathrm{~min}$ and observed using a fluorescence microscope (magnification, $\mathrm{x} 400$ ).
Dual luciferase reporter assay. The relationship between the 3'UTR of ITGA3 and miR-199a-5p was investigated using a dual luciferase reporter assay. HCT-116 cells were transfected with $300 \mathrm{ng} /$ well miR-199a-5p mimics or mimics NC, $300 \mathrm{ng} /$ well mutant (MUT) or wild-type (WT) 3'UTR ITGA3 and $100 \mathrm{ng}$ Renilla luciferase plasmid (pRL-TK; Promega Corporation) using Lipofectamine ${ }^{\circledR} 2000$ (Invitrogen; Thermo Fisher Scientific, Inc.). HCT-116 cells transfected with pRL-TK alone served as the negative control group. After co-transfection, the cells were cultured at $37^{\circ} \mathrm{C}$ for $24 \mathrm{~h}$. Subsequently, the luciferase activities in the different groups were analyzed using a Dual-Luciferase Reporter assay system (Promega Corporation), according to the manufacturer's protocol. Firefly luciferase activities were normalized to Renilla luciferase activities.

Immunohistochemical analysis (IHC). The expression of ITGA3 in CRC tissues and normal tissues was detected by IHC staining. The paraffin sections in different groups were dewaxed in xylene and hydrated using an ascending alcohol gradient. The tissues were boiled in citric acid buffer (pH 6.0) for $10 \mathrm{~min}$, followed by cooling to room temperature. The sections were blocked using goat serum (Beijing Solarbio Science \& Technology Co., Ltd.) for $30 \mathrm{~min}$ at room temperature, and incubated using an anti-ITGA3 antibody (cat. no. ab131055; 1:500; Abcam) at $4^{\circ} \mathrm{C}$ overnight. Following primary incubation, the sections were incubated with a goat anti-rabbit IgG $\mathrm{H} \& \mathrm{~L}$ horseradish peroxidase-conjugated secondary antibody (cat. no. ab6721; 1:500; Abcam) at $37^{\circ} \mathrm{C}$ for $20 \mathrm{~min}$. Subsequently, the sections were stained with DAB (OriGene Technologies, Inc.) at room temperature for $5 \mathrm{~min}$ and observed under a light microscope (magnification, $\mathrm{x} 400$ ).

Statistical analysis. Statistical analyses were performed using SPSS software (version 23.0; IBM Corp.). The differences between two groups were analyzed using the paired Student's t-test. The differences among multiple groups were analyzed by one-way ANOVA followed by Tukey's post-hoc test at the $95 \%$ confidence interval. $\mathrm{P}<0.05$ was considered to indicate a statistically significant difference.

\section{Results}

miR-199a-5p and ITGA3 expression is dysregulated in CRC tissues and cells. To determine the expression levels of miR-199a-5p and ITGA3 in CRC, total RNA was extracted from CRC and adjacent non-cancerous tissues. RT-qPCR was applied to evaluate the expression of miR-199a-5p and ITGA3 at the mRNA level. As presented in Fig. 1A and D, miR-199a-5p was significantly downregulated in CRC tissues and cancer cells compared with normal tissues. The expression of miR-199a-5p was significantly decreased in T2, T3 and T4 tumors compared with normal tissues, although no statistically significant differences were observed between normal tissues and T1 (Fig. 1A).

IHC staining indicated the upregulation of ITGA3 at the protein level in cancer tissues compared with normal tissues (Fig. 1C), which was consistent with the results detected in the cell lines (Fig. 1E and F). ITGA3 was significantly increased in T2, T3 and T4 tumors compared with normal tissues, 

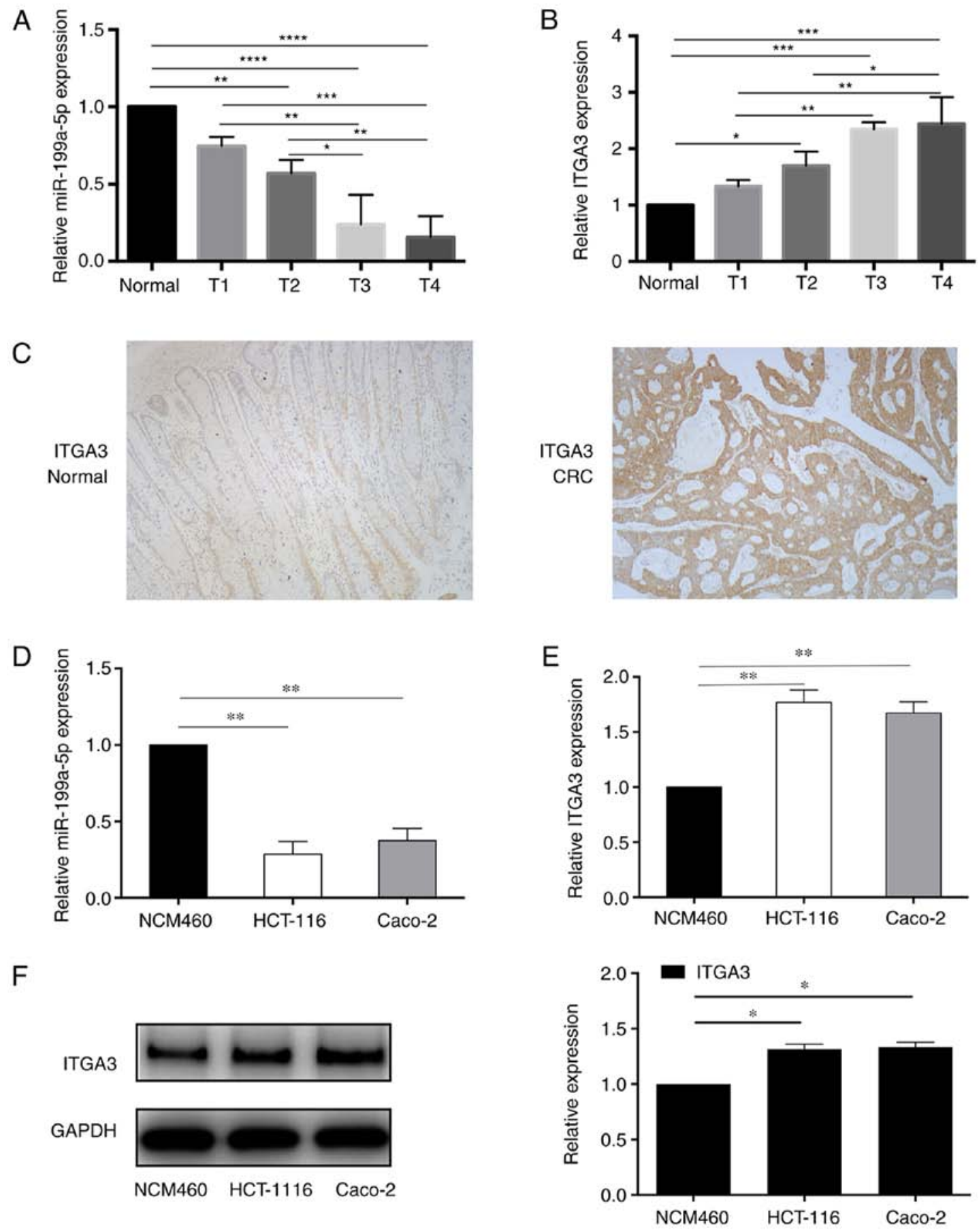

Figure 1. miR-199a-5p and ITGA3 levels are dysregulated in CRC tissues and cells. (A) The expression of miR-199a-5p was significantly decreased in CRC tissues, and the level was decreased in T2, T3 and T4 tumors compared with normal tissues. No statistically significant difference was observed between T1 and normal tissues. (B) RT-qPCR revealed that ITGA3 expression was upregulated in CRC tissues. ITGA3 was significantly increased in T2, T3 and T4 tumors compared with normal tissues, No significant difference was observed between T1 and normal tissues. (C) Immunohistochemical staining results indicated upregulated ITGA3 protein levels in CRC tissues compared with normal tissues. (D) RT-qPCR demonstrated that miR-199a-5p was downregulated in cancer cell lines HCT-116 and Caco-2. (E) RT-qPCR revealed that ITGA3 was upregulated in cancer cell lines HCT-116 and Caco-2 compared with the normal colon epithelial cell line NCM460. (F) Western blotting demonstrated that ITGA3 was upregulated in cancer cell lines HCT-116 and Caco-2 compared with NCM460 cells. ${ }^{*} \mathrm{P}<0.05,{ }^{* *} \mathrm{P}<0.01,{ }^{* * * *} \mathrm{P}<0.001$ and ${ }^{* * * * *} \mathrm{P}<0.0001$. CRC, colorectal cancer; RT-qPCR, reverse transcription-quantitative PCR; ITGA3, integrin $\alpha 3 \beta 1$; miR, microRNA; NC, negative control.

although the differences between normal tissues and T1 were not statistically significant (Fig. 1B).

These results suggested that miR-199a-5p expression was downregulated, whereas ITGA3 was upregulated in CRC tissues and cell lines, and their expression was partially associated with tumor stages.
Overexpression of miR-199a-5p suppresses the proliferation, migration and invasion of HCT116 cells. To assess the biological mechanism of miR-199a-5p in CRC progression, HCT-116 cells were transfected with miR-199a-5p mimics or mimics NC. RT-qPCR results suggested that miR-199a-5p expression was significantly increased in the miR-199a-5p mimics group 


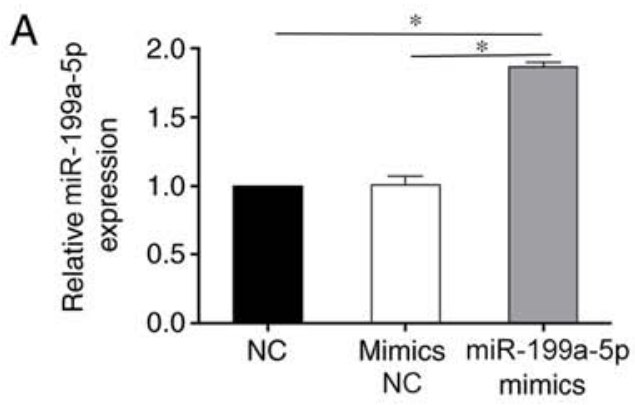

C

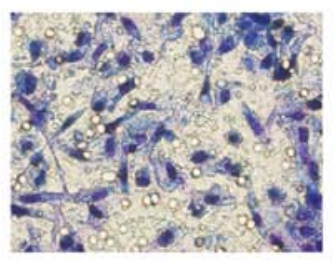

NC

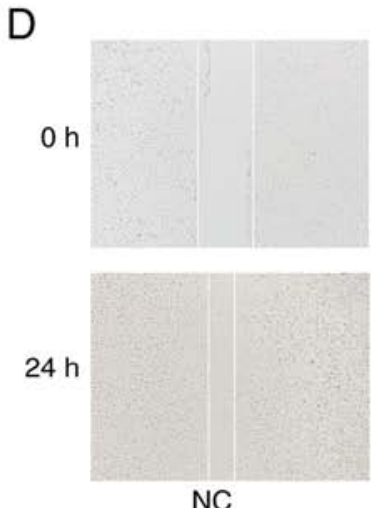

NC

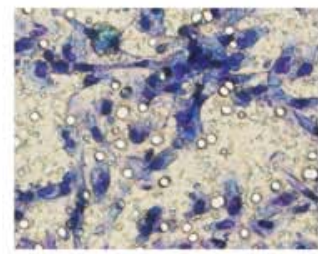

Mimics NC
B

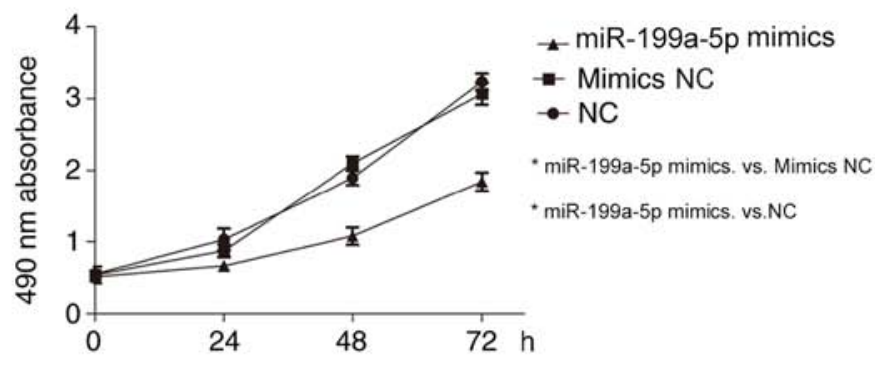

$\mathrm{E}$

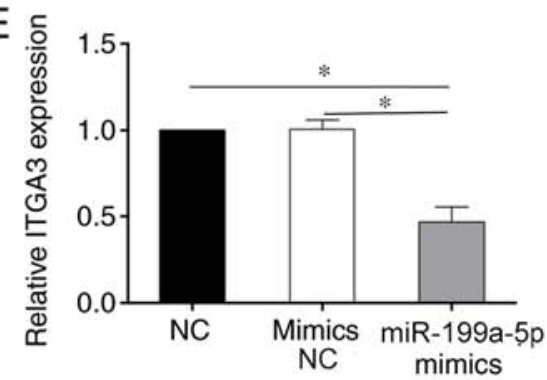

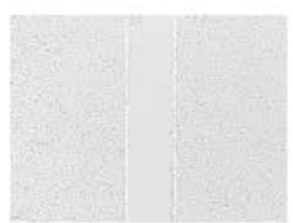

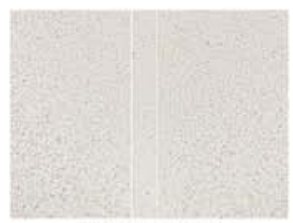

Mimics NC


miR-199a-5p mimics

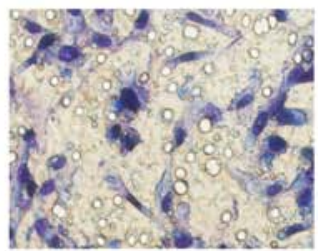

miR-199a-5p mimics

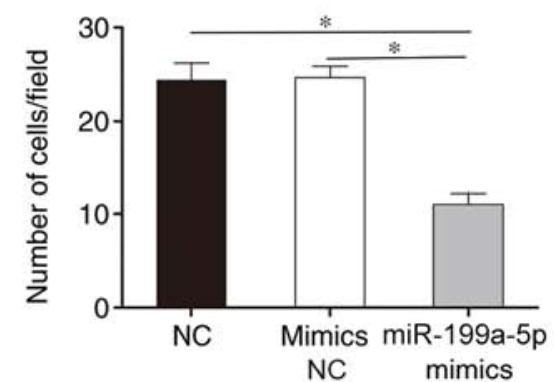

F

ITGA3

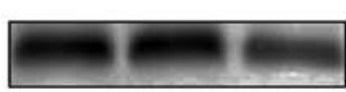

GAPDH



Figure 2. miR-199a-5p mimics inhibit the proliferation, migration and invasion of HCT-116 cells. (A) RT-qPCR results revealed that miR-199a-5p expression was significantly increased in cells transfected with miR-199a-5p mimics compared with the mimics NC and NC group. (B) MTT assay demonstrated that the miR-199a-5p mimics suppressed cell proliferation compared with that in the mimics NC and NC group. (C) The miR-199a-5p mimics suppressed cell invasion compared with that in the mimics NC and NC group. (D) Wound healing assay demonstrated that the miR-199a-5p mimics suppressed the migration of CRC cells compared with that in the mimics NC and NC group. (E) The mRNA expression of ITGA3 was decreased in the miR-199a-5p mimics group compared with that in the mimics NC and NC group. (F) The expression of ITGA3 was decreased in miR-199a-5p mimics group at the protein level compared with that in the NC group. " $\mathrm{P}<0.05$ and ${ }^{* *} \mathrm{P}<0.01$ vs. mimic NC or NC. RT-qPCR, reverse transcription-quantitative PCR; miR, microRNA; CRC, colorectal cancer; ITGA3, integrin $\alpha 3 \beta 1 ; \mathrm{NC}$, negative control.

compared with that in the mimics NC group (Fig. 2A). MTT, Transwell and wound healing assays were performed to evaluate the HCT-116 cell proliferation, invasion and migration. The MTT results demonstrated that miR-199a-5p mimics suppressed cell proliferation compared with the mimics NC group (Fig. 2B). Transwell assay results indicated the inhibition on tumor cell invasiveness by miR-199a-5p compared with the mimics NC group (Fig. 2C). Furthermore, wound healing assay revealed that miR-199a-5p mimics suppressed the migratory ability of HCT116 cells compared with the mimics NC group (Fig. 2D). These results demonstrated that miR-199a-5p suppressed the cell proliferation, migration and invasion in a CRC cell line. In addition, downregulated expression of ITGA3 was observed in the miR-199a-5p mimics group compared with the mimics NC at the mRNA and protein levels (Fig. 2E and F), which indicated that ITGA3 may be a direct or indirect target of miR-199a-5p. 
A

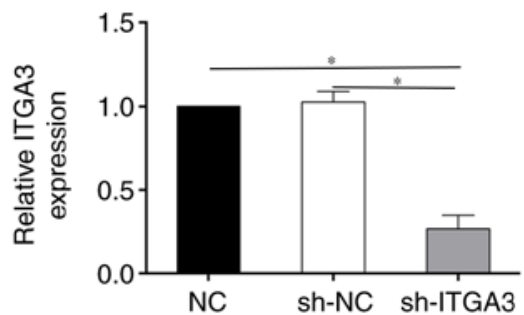

C



$\mathrm{B}$
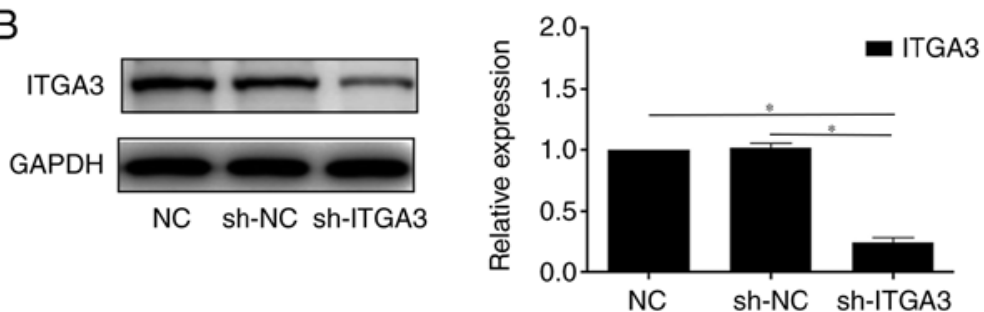

D
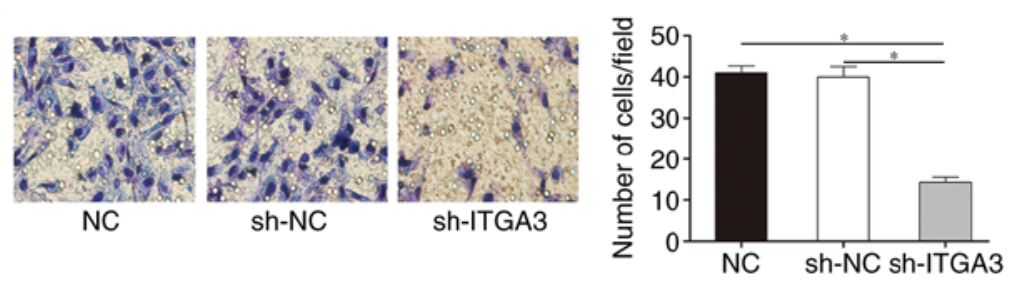
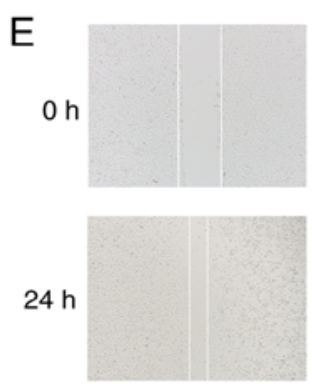

NC
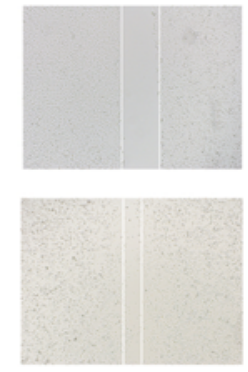

sh-NC

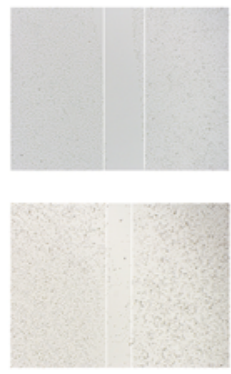

sh-ITGA3

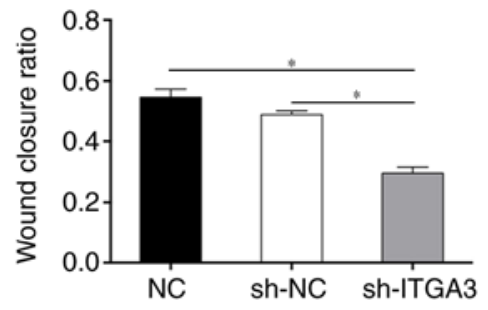

Figure 3. ITGA3 knockdown inhibits the proliferation, migration and invasion of HCT-116 cells. (A) RT-qPCR verified that the expression of ITGA3 was significantly decreased in the sh-ITGA3 group at the mRNA level compared with that in the sh-NC and NC group. (B) Western blotting results showed that the expression of ITGA3 was significantly decreased in the sh-ITGA3 group at the protein level compared with that in the sh-NC and NC group. (C) MTT assay results suggested that the cell proliferation was decreased in the sh-ITGA3 group compared with that in the sh-NC and NC group (D) Transwell assay demonstrated that the cell invasion ability was significantly decreased in the sh-ITGA3 group compared with the sh-NC and NC group. (E) Wound healing assay demonstrated that the migratory ability was significantly decreased in the sh-ITGA 3 group compared with the sh-NC and NC group. ${ }^{*} \mathrm{P}<0.05$ vs. sh-NC or NC. RT-qPCR, reverse transcription-quantitative PCR; sh, short hairpin; ITGA3, integrin $\alpha 3 \beta 1$; NC, negative control.

A

ITGA3

hsa-miR-199a-5p

ITGA3
5’ACACCUCCCCCUUUCACACUGGA3' WT |||||| 3'CUUGUCUAUCAGAUUUGUGACCC5' 5’ACACCUCCCCCUUUCCACUAUAA3' MUT

\section{$\mathrm{B}$}

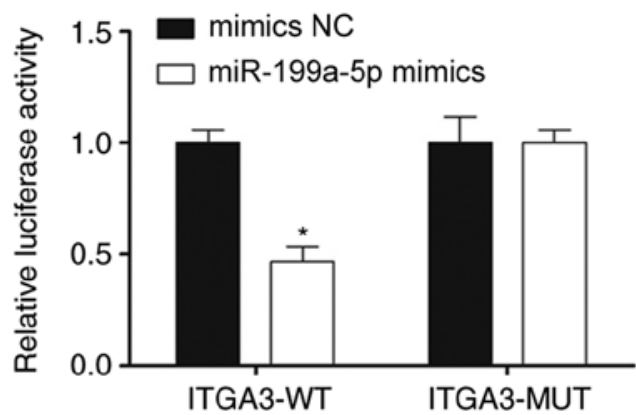

Figure 4. The 3'UTR of ITGA3 is a direct target of miR-199a-5p. (A) Bioinformatics analysis predicted that miR-199a-5p could bind to 3'UTR of ITGA3. (B) Dual luciferase reporter assay confirmed that luciferase activity was suppressed in HCT-116 cells co-transfected with ITGA3-WT and miR-199a-5p mimics, but not ITGA3-MUT. "P<0.05 vs. miR-NC. 3'UTR, 3' untranslated region; miR, microRNA; ITGA3, integrin $\alpha 3 \beta 1$; NC, negative control; WT, wild-type; MUT, mutant.

ITGA3 knockdown inhibits the proliferation, migration and invasion in HCT-116 cells. To further investigate the potential role of ITGA3 in HCT-116 cells, cells were transfected with sh-ITGA3 or sh-NC. RT-qPCR and western blotting demonstrated that the level of ITGA3 was significantly downregulated in cells transfected with sh-ITGA3 compared with those transfected with sh-NC (Fig. 3A and B). The MTT assay was performed to detect cell proliferation; as presented in Fig. 3C, the proliferative ability was remarkably decreased in cells transfected with sh-ITGA3 compared with sh-NC. The Transwell (Fig. 3D) and wound healing (Fig. 3E) assay results revealed that the invasive and migratory abilities were significantly decreased in the sh-ITGA3 group compared with the sh-NC groups. These data indicated that knockdown of ITGA3 inhibited the proliferation, migration and invasion of HCT-116 cells. 

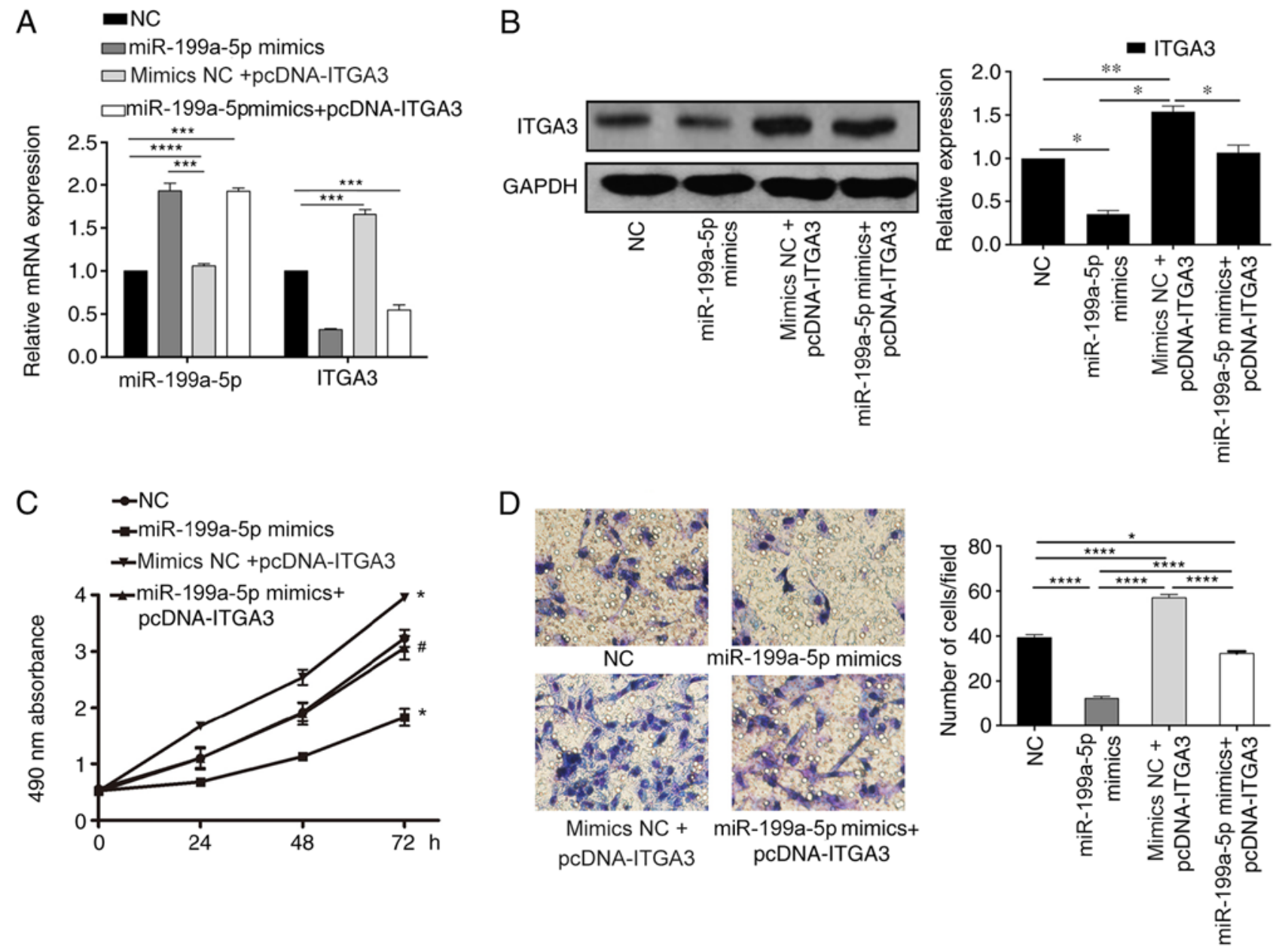
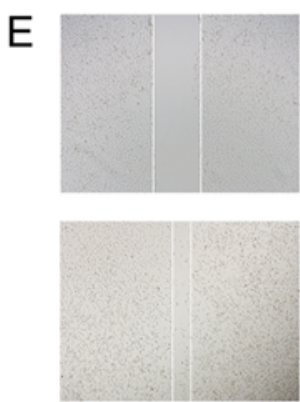

NC
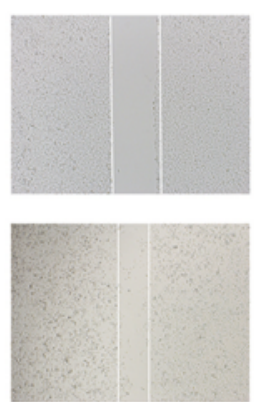

miR-199a-5p mimics
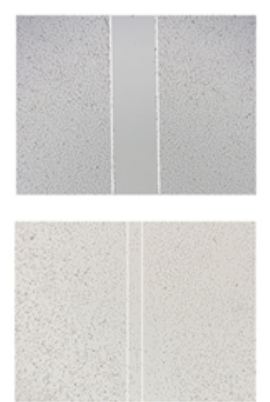

Mimics NC + miR-199a-5p mimics+ PcDNA-ITGA3 PcDNA-ITGA3

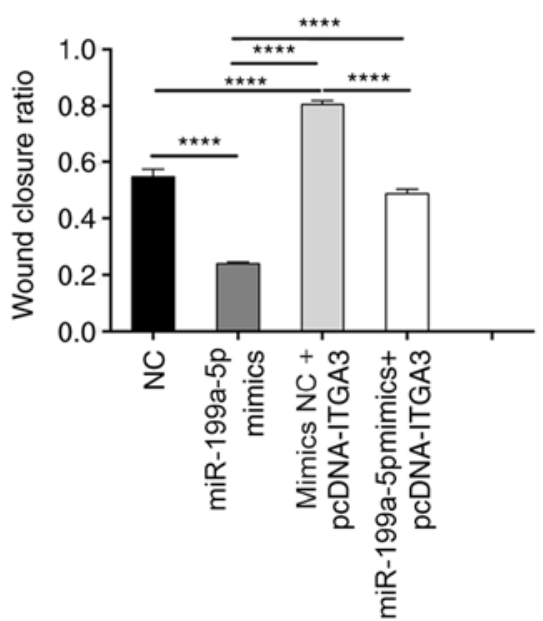

Figure 5. miR-199a-5p suppresses the proliferative, migratory and invasive abilities of CRC cells by negatively regulating ITGA3 expression. (A) RT-qPCR results showed that the expression of ITGA3 was significantly decreased in the miR-199a-5p mimics + pcDNA-ITGA3 group compared with the mimics $\mathrm{NC}+$ pcDNA-ITGA3 group at the mRNA level. (B) Western blotting results demonstrated that the expression of ITGA3 was significantly decreased in the miR-199a-5p mimics + pcDNA-ITGA3 group compared with the mimics NC + pcDNA-ITGA3 group at the protein level. (C) The MTT assay revealed that overexpression of miR-199a-5p and ITGA3 together increased the cell proliferation compared with the miR-199a-5p mimics alone. ${ }^{*} \mathrm{P}<0.05$ vs. NC; ${ }^{*} \mathrm{P}<0.05$ vs. miR-199-5p mimics. (D) Transwell results demonstrated that the cell invasive ability was decreased in cells co-transfected with miR-199a-5p mimics and pcDNA-ITGA3 compared with that in cells transfected with mimics NC + pcDNA-ITGA3. (E) Wound healing assay demonstrated that overexpression of ITGA3 attenuated the effects of miR-199a-5p on cell migration. ${ }^{*} \mathrm{P}<0.05,{ }^{* * *} \mathrm{P}<0.01,{ }^{* * *} \mathrm{P}<0.001$ and ${ }^{* * * * *} \mathrm{P}<0001$. ITGA3, integrin $\alpha 3 \beta 1$; RT-qPCR, reverse transcription-quantitative PCR; miR, microRNA; NC, negative control.

ITGA3 3'UTR is a direct target of miR-199a-5p. As a negative association was observed between miR-199a-5p and ITGA3 in CRC tissues and cell lines, bioinformatics analysis was used to predict whether miR-199a-5p bound to 3'UTR of ITGA3 (Fig. 4A). To further determine the connection between miR-199a-5p and ITGA3, the dual luciferase reporter assay was performed. As presented in Fig. 4B, the luciferase activity in cells transfected with ITGA3-WT was significantly 
A
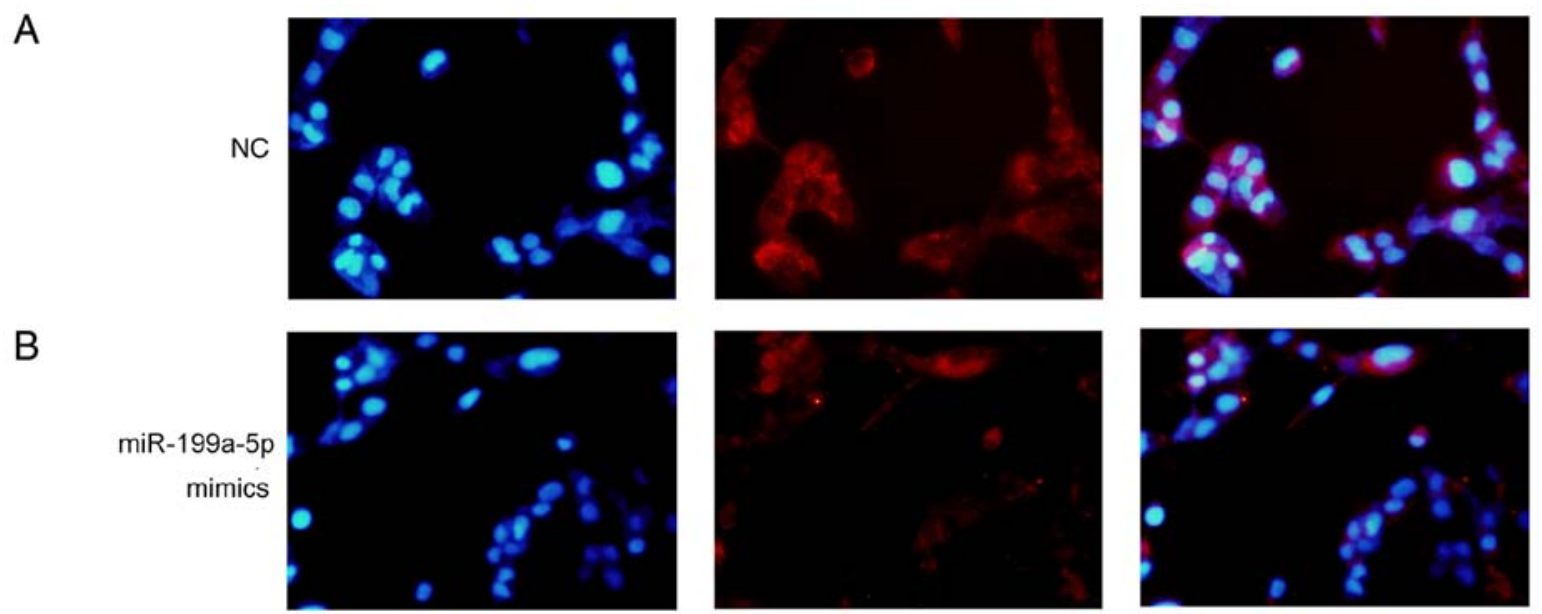

Mimics NC+
pcDNA ITGA3
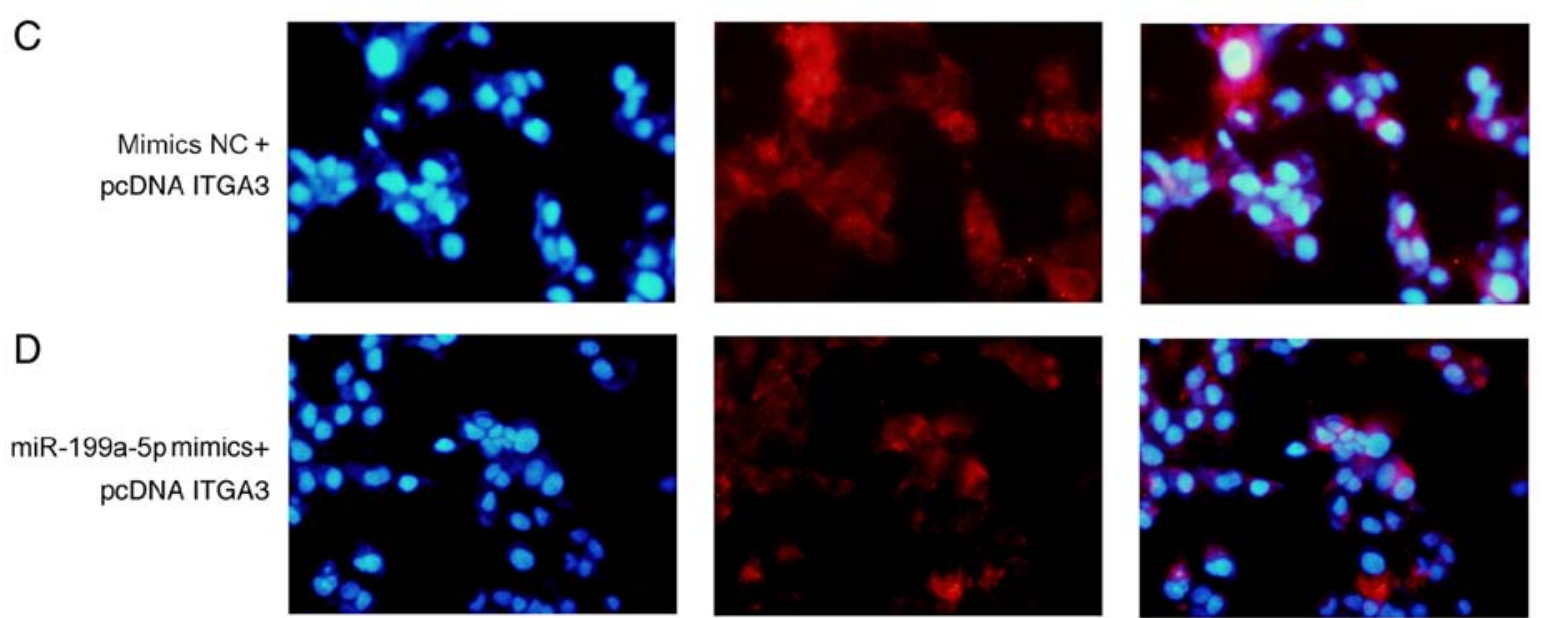

DAPI

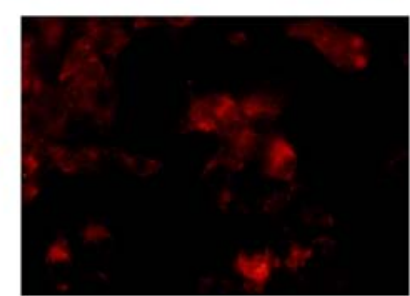

$\mathrm{N}$-cadherin

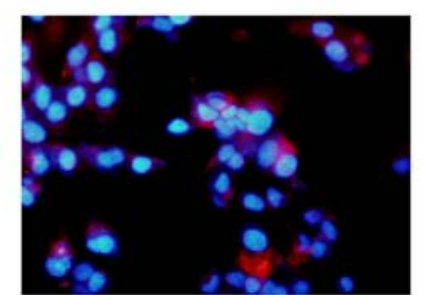

Merge

Figure 6. $\mathrm{N}$-cadherin is increased in the mimics NC + pcDNA ITGA3 group compared with the miR-199a-5p mimics + pcDNA ITGA3 group. (A) NC group. (B) miR-199a-5p mimics group. (C) Mimics NC + pcDNA ITGA3 group. (D) miR-199a-5p mimics + pcDNA ITGA3 group. miR, microRNA; ITGA3, integrin $\alpha 3 \beta 1 ; \mathrm{NC}$, negative control.

suppressed compared with the ITGA3-MUT group, which suggested that miR-199a-5p bound to the 3'UTR of ITGA3 to negatively regulate ITGA3 expression.

miR-199a-5p suppresses cell proliferative, migratory and invasive abilities in CRC cells by negatively regulating ITGA3 expression. To further confirm the proliferative, migratory and invasive functions of the miR-199a-5p/ITGA3 axis in CRC, mimics NC + pcDNA ITGA3 or miR-199a-5p mimics + pcDNA ITGA3 were co-transfected into HCT-116 cells. As presented in Fig. 5A and B, ITGA3 expression levels were decreased in the miR-199a-5p mimics group compared with the miR-199a-5p mimics NC + pcDNA ITGA3 group. The MTT results demonstrated that overexpression of miR-199a-5p and ITGA3 together increased the cell proliferation compared with that in cells transfected with the miR-199a-5p mimics alone (Fig. 5C). The results of the Transwell and wound healing assay also demonstrated that overexpression of ITGA3 attenuated the effects of the miR-199a-5p mimics on cell invasion and migration, respectively (Fig. 5D and E).

The expression levels of E-cadherin and $\mathrm{N}$-cadherin were analyzed by immunofluorescence assay. The expression of $\mathrm{N}$-cadherin increased in the miR-199a-3p mimics + pcDNA-ITGA3 group compared with the
miR-199a-3p mimics group (Fig. 6B and C), whereas the expression of E-cadherin decreased in the miR-199a-3p mimics + pcDNA-ITGA3 group compared with the miR-199a-3p mimics group (Fig. 7B and C). The expression levels of E-cadherin decreased and the expression levels of N-cadherin increased in the miR-199a-5p mimics $\mathrm{NC}+$ pcDNA ITGA3 group compared with the NC group. The results suggested that ITGA3 overexpression rescued miR-199a-3p-mediated inhibition of EMT, indicating that the tumor suppressive activity of miR-199a-5p during CRC was established by inhibiting the expression of ITGA3.

\section{Discussion}

Although great progress has been achieved in tumor diagnosis and treatment, the mortality rates of various types of cancer remain high worldwide, especially those of CRC (29). The surgical treatment of early stage CRC can effectively increase the survival period, whereas the prognosis for patients with late stage CRC remains in need of further improvement (30). Accumulating evidence has suggested that the invasion and migration are crucial reasons for poor prognosis at the late stage of cancers $(31,32)$. Thus, it is crucial to investigate specific and effective prognostic biomarkers for CRC. The 
A
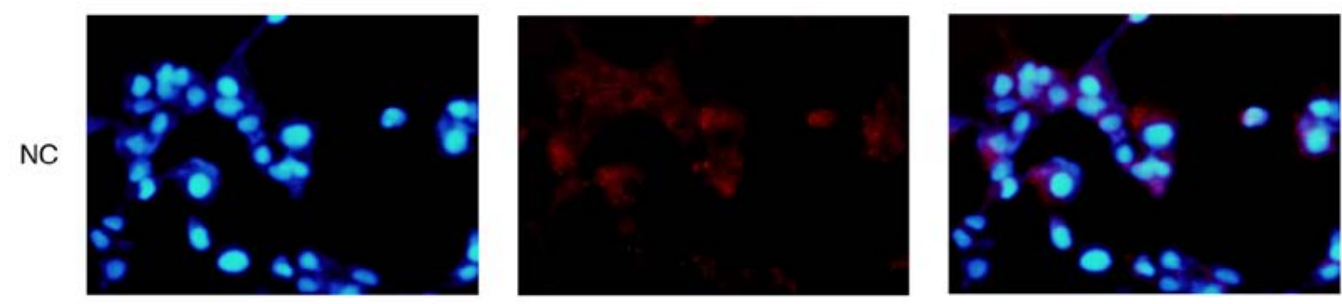

B
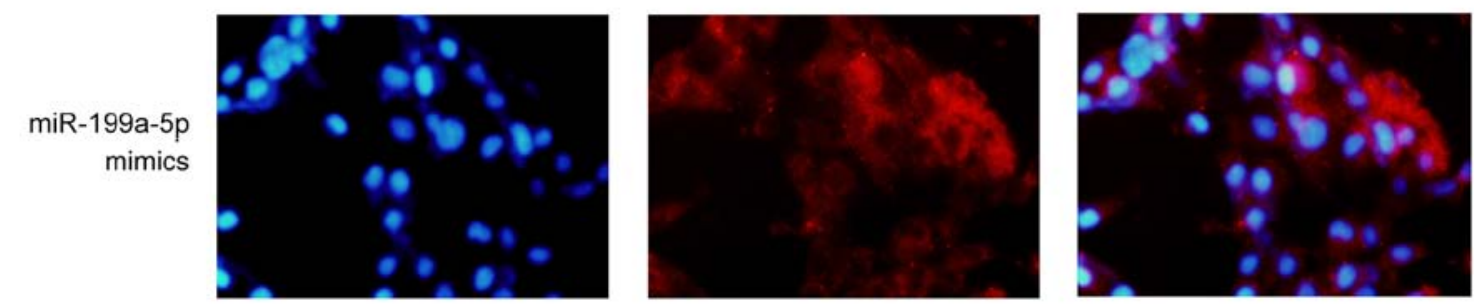

C
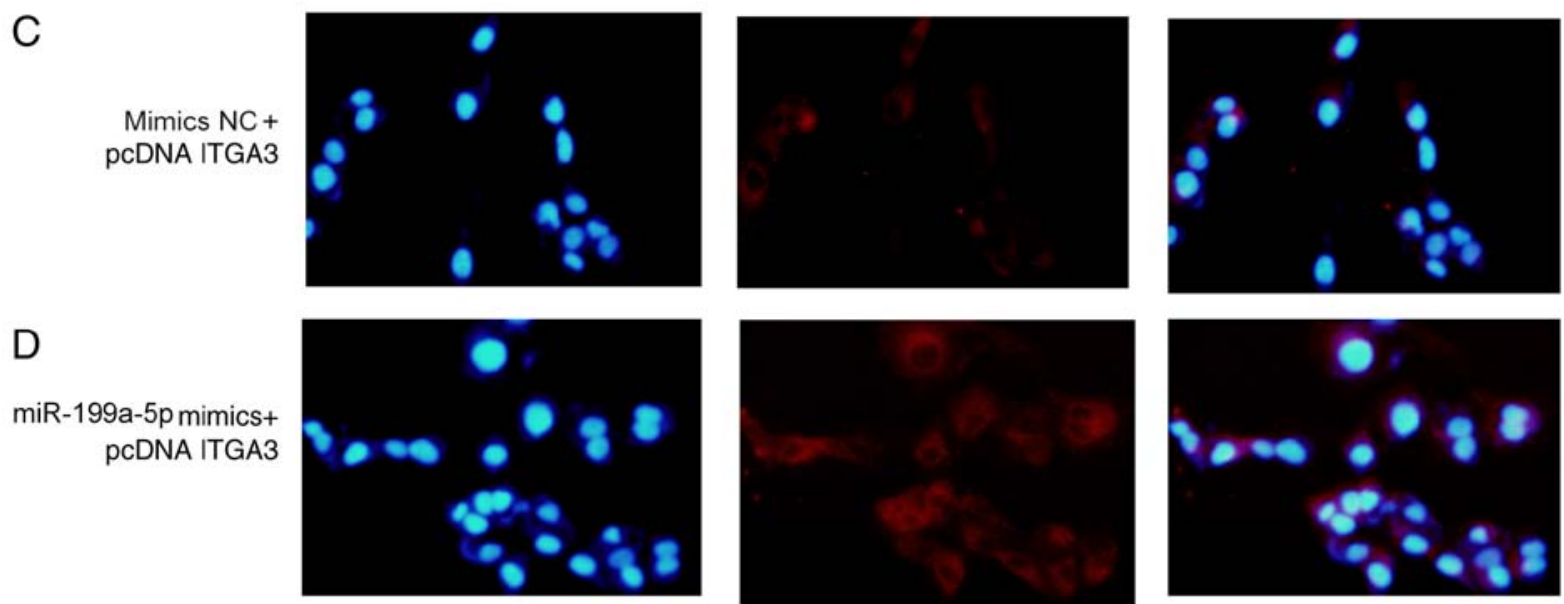

DAPI

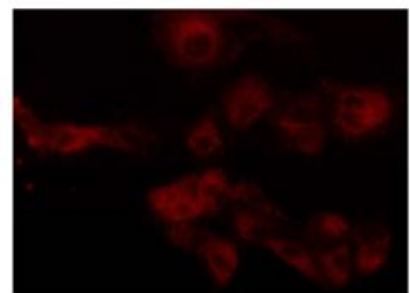

E-cadherin

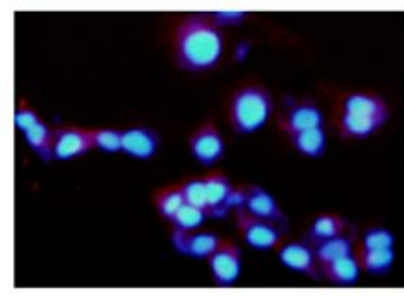

Merge

Figure 7. E-cadherin is decreased in mimics NC + pcDNA ITGA3 group, which is rescued in the miR-199a-5p mimics + pcDNA ITGA3 group. (A) NC group. (B) miR-199a-5p mimics group. (C) Mimics NC + pcDNA ITGA3 group. (D) miR-199a-5p mimics + pcDNA ITGA3 group. miR, microRNA; ITGA3, integrin $\alpha 3 \beta 1$; NC, negative control.

biological functions of miRNAs in the development of tumors have attracted the attention of researchers (33). The present study focused on whether miR-199a-5p, a rarely reported miRNA in CRC, may function as a tumor suppressor in CRC. The results demonstrated that the expression of miR-199a-5p was downregulated, whereas ITGA3 expression was upregulated in CRC tissues, which was consistent with the results in CRC cells. The 3'UTR of ITGA3 was predicted to be a binding target for miR-199a-5p via bioinformatics analysis. Based on the above results, it was hypothesized that miR-199a-5p may regulate the progression of colon cancer by regulating the expression of ITGA3.

Despite the definition of miRNAs as non-coding RNAs, they have been demonstrated to be involved in $>60 \%$ of human gene expression by participating in post-transcriptional regulation (34). Dysregulation in miRNAs results in a variety of diseases, including malignant tumors $(3,35)$. Previous studies have demonstrated that miRNA dysregulation is involved in cell proliferation, invasion and tumor metastasis $(36,37)$. Yuan et al (38) reported that elevated miR-199a-5p promoted the apoptosis and suppressed the proliferation in oral submucous fibrocytes, which was consistent with the results of the present study indicating cell proliferation inhibition. Furthermore, a previous study reported that upregulated
miR-199a-5p expression alleviated sustained endoplasmic reticulum stress, and thus protected hepatocytes from bile acid-induced cell death (18). The results of the present study demonstrated that miR-199a-5p was downregulated in CRC, and miR-199a-5p mimics suppressed CRC cell invasion, migration and proliferation. These results were in accordance with a previous study by Chao et al (39), which demonstrated that downregulated miR-199a-5p was involved in the migration and invasion of the CRC cell line DLD-1. In addition, the present study demonstrated that ITGA3 expression levels decreased when HCT-116 cells were transfected with miR-199a-5p mimics, which suggested that miR-199a-5p may negatively regulate ITGA 3 expression.

As a member of the integrin family, ITGA3 participates in the Wnt/TGF- $\beta$ signaling pathway among cells and extracellular matrix. It has been reported that ITGA3 may be involved in cell proliferation, migration and invasion. Previously, studies have reported the association between overexpressed ITGA3 and invasion in gastric carcinomas $(40,41)$. Furthermore, ITGA3 has been considered as a biomarker for tongue squamous cell carcinoma cervical lymph node metastasis (42). The results of the present study demonstrated an increase of ITGA3 expression in CRC tissues and cell lines, and knockdown of ITGA3 inhibited CRC cell 
proliferation, invasion and migration. Furthermore, luciferase reporter assay confirmed that ITGA3 was a direct target of miR-199a-5p. In addition, the expression of EMT biomarkers was investigated in the different groups, and the results suggested that miR-199a-5p mimics significantly inhibited the EMT process of CRC cells, whereas overexpression of ITGA3 reversed the effects of miR-199a-5p on the EMT process. These results also supported the tumor-suppressive role of miR-199a-5p by downregulating ITGA3.

In conclusion, the present study demonstrated that miR-199-5p suppressed ITGA3 expression by directly binding to its 3'UTR, and thus may exert a tumor-suppressive role in CRC, indicating that miR-199a-5p may be a potential candidate for gene regulation-based tumor therapy. In the present study, miR-199a-5p and IGTA3 were detected in tumor tissues and cell lines; in our future work, the expression of miR-199a-5p will be further studied in the blood, and the feasibility of using it as a biomarker of $\mathrm{CRC}$ will be evaluated.

\section{Acknowledgements}

Not applicable.

\section{Funding}

No funding was received.

\section{Availability of data and materials}

The datasets used and/or analyzed during the current study are available from the corresponding author on reasonable request.

\section{Authors' contributions}

LT and MC performed the majority of the experiments, wrote the manuscript and analyzed the data. QH performed the western blotting experiments. QY and CZ designed the study and edited the manuscript. All authors read and approved the final manuscript.

\section{Ethics approval and consent to participate}

Not applicable.

\section{Patient consent for publication}

Not applicable.

\section{Competing interests}

The authors declare that they have no competing interests.

\section{References}

1. Blomme B, Deroanne C, Hulin A, Lambert C, Defraigne JO, Nusgens B, Radermecker M and Colige A: Mechanical strain induces a pro-fibrotic phenotype in human mitral valvular interstitial cells through RhoC/ROCK/MRTF-A and Erk1/2 signaling pathways. J Mol Cell Cardiol 135: 149-159, 2019.

2. Zhao L and Wang Z: MicroRNAs: Game changers in the regulation of $\alpha$-synuclein in Parkinson's disease. Parkinsons Dis 2019: $1743183,2019$.
3. Zhao X, Chen GQ and Cao GM: Abnormal expression and mechanism of miR-330-3p/BTG1 axis in hepatocellular carcinoma. Eur Rev Med Pharmacol Sci 23: 6888-6898, 2019.

4. Yang L, Hong Q, Xu SG, Kuang XY, Di GH, Liu GY, Wu J, Shao ZM and Yu SJ: Downregulation of transgelin 2 promotes breast cancer metastasis by activating the reactive oxygen species/nuclear factor- $\kappa \mathrm{B}$ signaling pathway. Mol Med Rep 20: 4045-4258, 2019.

5. Lin JS, Piper MA, Perdue LA, Rutter C, Webber EM, O'Connor E, Smith $\mathrm{N}$ and Whitlock EP: Screening for colorectal cancer: A systematic review for the U.S. Preventive Services Task Force. Agency for Healthcare Research and Quality (US), Rockville, MD, 2016.

6. Brenner H, Kloor M and Pox CP: Colorectal cancer. Lancet 383: 1490-1502, 2014.

7. Koliarakis I, Psaroulaki A, Nikolouzakis TK, Kokkinakis M, Sgantzos M, Goulielmos G, Androutsopoulos VP, Tsatsakis A and Tsiaoussis $\mathrm{J}$ : Intestinal microbiota and colorectal cancer: A new aspect of research. J BUON 23: 1216-1234, 2018.

8. Lin F, Zhang P, Zuo Z, Wang F, Bi R, Shang W, Wu A, Ye J, Li S, Sun X, et al: Thioredoxin-1 promotes colorectal cancer invasion and metastasis through crosstalk with S100P. Cancer Lett 401: 1-10, 2017.

9. Nieto MA, Huang RY, Jackson RA and Thiery JP: EMT: 2016. Cell 166: 21-45, 2016.

10. Derynck R and Weinberg RA: EMT and cancer: More than meets the eye. Dev Cell 49: 313-316, 2019.

11. Xu D, Li J, Li RY, Lan T, Xiao C and Gong P: PD-L1 expression is regulated by NF- $\kappa \mathrm{B}$ during EMT signaling in gastric carcinoma. Onco Targets Ther 12: 10099-10105, 2019.

12. Szeder B, Tárnoki-Zách J, Lakatos D, Vas V, Kudlik G, Merő B, Koprivanacz K, Bányai L, Hámori L, Róna G, et al: Absence of the Tks4 scaffold protein induces epithelial-mesenchymal transition-like changes in human colon cancer cells. Cells 8: $1343,2019$.

13. Zhang HD, Jiang LH, Sun DW, Li J and Ji ZL: The role of miR130a in cancer. Breast Cancer 24: 521-527, 2017.

14. Mellis D and Caporali A: MicroRNA-based therapeutics in cardiovascular disease: Screening and delivery to the target. Biochem Soc Trans 46: 11-21, 2018.

15. Di Leva G, Garofalo M and Croce CM: MicroRNAs in cancer. Annu Rev Pathol 9: 287-314, 2014.

16. Li Y, Zhang G, Wu B, Yang W and Liu Z: miR-199a-5p represses protective autophagy and overcomes chemoresistance by directly targeting DRAM1 in acute myeloid leukemia. J Oncol 2019: 5613417, 2019.

17. Qu D, Yang Y and Huang X: miR-199a-5p promotes proliferation and metastasis and epithelial-mesenchymal transition through targeting PIAS3 in cervical carcinoma. J Cell Biochem 120: 13562-13572, 2019.

18. Dai BH, Geng L, Wang Y, Sui CJ, Xie F, Shen RX, Shen WF and Yang JM: microRNA-199a-5p protects hepatocytes from bile acid-induced sustained endoplasmic reticulum stress. Cell Death Dis 4: e604, 2013.

19. Ahmadi A, Khansarinejad B, Hosseinkhani S, Ghanei M and Mowla SJ: miR-199a-5p and miR-495 target GRP78 within UPR pathway of lung cancer. Gene 620: 15-22, 2017.

20. Zhu QD, Zhou QQ, Dong L, Huang Z, Wu F and Deng X: MiR-199a-5p inhibits the growth and metastasis of colorectal cancer cells by targeting ROCK1. Technol Cancer Res Treat 17: $1533034618775509,2018$.

21. Kim BK, Yoo HI, Kim I, Park J and Kim YS: FZD6 expression is negatively regulated by miR-199a-5p in human colorectal cancer. BMB Rep 48: 360-366, 2015.

22. Weber C, Alon R, Moser B and Springer TA: Sequential regulation of alpha 4 beta 1 and alpha 5 beta 1 integrin avidity by $\mathrm{CC}$ chemokines in monocytes: Implications for transendothelial chemotaxis. J Cell Biol 134: 1063-1073, 1996.

23. Desgrosellier JS and Cheresh DA: Integrins in cancer: Biological implications and therapeutic opportunities. Nat Rev Cancer 10: 9-22, 2010.

24. Sun CC, Qu XJ and Gao ZH: Arginine-glycine-aspartate-binding integrins as therapeutic and diagnostic targets. Am J Ther 23: e198-e207, 2016.

25. Nagata M, Noman AA, Suzuki K, Kurita H, Ohnishi M, Ohyama T, Kitamura N, Kobayashi T, Uematsu K, Takahashi K, et al: ITGA3 and ITGB4 expression biomarkers estimate the risks of locoregional and hematogenous dissemination of oral squamous cell carcinoma. BMC Cancer 13: 410, 2013. 
26. Jiao Y, Li Y, Liu S, Chen Q and Liu Y: ITGA3 serves as a diagnostic and prognostic biomarker for pancreatic cancer. Onco Targets Ther 12: 4141-4152, 2019.

27. Zhang H, Cui X, Cao A, Li X and Li L: ITGA3 interacts with VASP to regulate stemness and epithelial-mesenchymal transition of breast cancer cells. Gene 734: 144396, 2020.

28. Li GF, Li ZB, Zhuang SJ and Li GC: Inhibition of microRNA-34a protects against propofol anesthesia-induced neurotoxicity and cognitive dysfunction via the MAPK/ERK signaling pathway. Neurosci Lett 675: 152-159, 2018.

29. Heo G, Kang D, Park C, Kim SJ, Choo J, Lee Y, Yoo JW, Jung Y, Lee J, Kim ND, et al: Pro-apoptotic effect of the novel benzylidene derivative MHY695 in human colon cancer cells. Oncol Lett 18: 3256-3264, 2019

30. Fu J, Wu L, Ge C, Xu T, Li D, Fu W, Wang L and Du J: De-escalating chemotherapy for stage II colon cancer? Therap Adv Gastroenterol 12: 1756284819867553, 2019.

31. Luo W, Gao F, Li S and Liu L: FoxM1 promotes cell proliferation, invasion, and stem cell properties in nasopharyngeal carcinoma. Front Oncol 8: 483, 2018

32. Dhamija S and Diederichs S: From junk to master regulators of invasion: lncRNA functions in migration, EMT and metastasis. Int J Cancer 139: 269-280, 2016.

33. Xu TJ, Qiu P, Zhang YB, Yu SY, Xu GM and Yang W: MiR-148a inhibits the proliferation and migration of glioblastoma by targeting ITGA9. Hum Cell 32: 548-556, 2019.

34. Norouzinia M, Azodi MZ, Seyfi DN, Kardan A, Naseh A and Akbari Z: Predication of hub target genes of differentially expressed microRNAs contributing to infection in gastric non-cancerous tissue. Gastroenterol Hepatol Bed Bench 12 (Suppl 1): S44-S50, 2019.

35. Zhang W, Xu J, Wang K, Tang X and He J: miR1393p suppresses the invasion and migration properties of breast cancer cells by targeting RAB1A. Oncol Rep 42: 1699-1708, 2019.
36. Dai X, Liang Z, Liu L, Guo K, Xu S and Wang H: Silencing of MALAT1 inhibits migration and invasion by sponging miR13p in prostate cancer cells. Mol Med Rep 20: 3499-3508, 2019.

37. Ye K, Xu C and Hui T: MiR-34b inhibits the proliferation and promotes apoptosis in colon cancer cells by targeting Wnt/ $\beta$-catenin signaling pathway. Biosci Rep 39: BSR20191799, 2019.

38. Yuan Y, Li N, Zeng L, Shen Z and Jiang C: Pathogenesis investigation of miR-199-5p in oral submucous fibrosis based on bioinformatics analysis. Oral Dis 25: 456-465, 2019.

39. Chao CC, Wu PH, Huang HC, Chung HY, Chou YC, Cai BH and Kannagi R: Downregulation of miR-199a/b-5p is associated with GCNT2 induction upon epithelial-mesenchymal transition in colon cancer. FEBS Lett 591: 1902-1917, 2017.

40. Song B, Du J, Feng Y, Gao YJ and Zhao JS: Co-expressed differentially expressed genes and long non-coding RNAs involved in the celecoxib treatment of gastric cancer: An RNA sequencing analysis. Exp Ther Med 12: 2455-2468, 2016.

41. Ura H, Denno R, Hirata K, Yamaguchi K and Yasoshima T: Separate functions of alpha2beta1 and alpha3betal integrins in the metastatic process of human gastric carcinoma. Surg Today 28: 1001-1006, 1998.

42. Kurokawa A, Nagata M, Kitamura N, Noman AA, Ohnishi M, Ohyama T, Kobayashi T, Shingaki S and Takagi R; Oral, Maxillofacial Pathology and Surgery Group: Diagnostic value of integrin alpha3, beta4, and beta5 gene expression levels for the clinical outcome of tongue squamous cell carcinoma. Cancer 112: 1272-1281, 2008.

cc) (i) $\odot$ This work is licensed under a Creative Commons

Cy NO NO Attribution-NonCommercial-NoDerivatives 4.0 International (CC BY-NC-ND 4.0) License. 